\title{
Ontogeny of Single Glomerular Perfusion Rate in Fetal and Newborn Lambs
}

\author{
JEAN E. ROBILLARD, ${ }^{(31)}$ DOUGLAS N. WEISMANN, AND \\ PETER HERIN WITH THE TECHNICAL ASSISTANCE OF BRIDGET CONSAMUS, \\ CHRISTINE SESSIONS, ELLEN VANBELL, AND HUGH SHRAGER \\ Department of Pediatrics, University of Iowa College of Medicine, Iowa City, Iowa, USA, and \\ Department of Pediatrics, Karolinska Institutet [P.H.], S:t Goran's Children's Hospital, Stockholm, Sweden
}

\begin{abstract}
Summary
The developmental pattern of regional glomerular density and glomerular perfusion rate (GPR) was studied in 20 chronically catheterized fetal lambs between 106 and 140 days of gestation (term, 145 days) and in six newborn lambs between 3 and 19 days of age. The present study demonstrates for the first time in lambs that the nephrogenic zone disappears around 130 days of gestation and that the total glomerular counts per kidney in fetuses over 130 days (468296 \pm 41173 glomeruli per kidney) is not significantly different than in newborn lambs $(433704 \pm 21553)$. Glomerular density, determined in four cortical zones (zone I being the outermost portion of the cortex) did not show any significant changes during fetal life; however, significant decreases in glomerular density were observed in each cortical zone after birth. The relative distribution of glomeruli during fetal life decreased in the outer portion (zones I and II) and increased in the inner portion (zones III and IV) of the cortex as fetuses matured and approached term. After birth, this difference became even more prominent; the outer cortical fraction (zone I) decreased from $49.6 \pm 2.9 \%$ in fetuses of less than 120 days to $37.8 \pm 1.5 \%(P<0.05)$ in newborn lambs, whereas the fraction found in zone III increased from $14.9 \pm 1.3 \%$ to $20.8 \pm 0.7 \%(P<0.05)$. Small but significant increases in glomerular filtration rate (GFR) $(P<0.01)$ and total renal blood flow $(P<0.05)$ were observed during fetal life: GFR and total renal blood flow increased, respectively, from $1.84 \pm 0.11$ and 37 $\pm 2 \mathrm{ml} / \mathrm{min}$ in fetuses $<120$ days to $3.05 \pm 0.2$ and $46 \pm 4 \mathrm{ml} / \mathrm{min}$ in fetuses $>130$ days gestation. During the same period, filtration fraction (FF) did not increase significantly whereas a significant $(P<0.01) 58 \%$ increase in $\mathbf{F F}$ was observed after birth: FF increased from $10.16 \pm 0.74 \%$ in fetuses $>130$ days gestation to $16.12 \pm 1.66 \%$ in newborn lambs. Renal vascular resistance decreased from $1.03 \pm 0.08 \mathrm{~mm} \mathrm{Hg} \cdot \mathrm{ml}^{-1} \cdot \mathrm{min}^{-1}$ in fetuses $>130$ days to $0.51 \pm 0.05 \mathrm{~mm} \mathrm{Hg} \cdot \mathrm{ml}^{-1} \cdot \mathrm{min}^{-1}(P<0.01)$ in newborn lambs. Glomerular perfusion rate (GPR), computed for each cortical zone did not change significantly during the last trimester of gestation. After birth, GPR increased almost three times in zones I and II (from $69.2 \pm 8.9$ and $53.6 \pm 4.2 \mathrm{nl} / \mathrm{min}$ in fetuses $>130$ days to $206.9 \pm 16.8$ and $161.3 \pm 20.7 \mathrm{nl} / \mathrm{min}$ in newborn lambs, respectively), doubled in zone III (from $55.6 \pm 10 \mathrm{nl} / \mathrm{min}$ in fetuses $>130$ days to $119.5 \pm 8.9 \mathrm{nl} / \mathrm{min}$ in newborn lambs) and remained unchanged in zone IV when compared to fetal GPR values. After birth, the increase in GFR correlated closely with the GPR increase in zone $I(r=0.87)$ and zone $I I(r=0.87)$, suggesting that the developmental pattern of GFR after birth may depend on the increase in GPR in the outer zones of the renal cortex.
\end{abstract}

\section{Speculation}

The addition of new nephron units may be an important determinant of glomerular filtration rate (GFR) in fetuses of less than 130 days of gestation. In fetuses over 130 days of gestation, the addition of new nephron units is no longer a factor to explain the increase in fetal GFR but other factors such as increases in surface area for filtration, effective filtration pressure and capillary filtration coefficient may then play an important role. After birth, one can speculate that a decrease in glomerular vascular resistance is a major determinant in the postnatal increase in glomerular perfusion rate and GFR.

Previous studies $(5,13,14,16)$ have demonstrated that the cortical blood flow is distributed preferentially to the juxtamedullary area of the cortex during early postnatal life, and with maturation, the development of cortical flow follows a centrifugal pattern. Spitzer and Brandis (26) also demonstrated that the maturation of glomerular filtration rate (GFR) closely follows the developmental pattern of cortical blood flow. More recently, Aperia and Herin (3), studying factors modulating the changes in GFR during maturation, have suggested that glomerular perfusion rate (GPR) is an important determinant of the increase in GFR during postnatal life.

Studies from our laboratory have demonstrated that during fetal life GFR increases at the same rate as the fetal body weight and kidney weight $(18,21)$. These observations are contrary to what occurs after birth, where the increase in GFR is disproportionately higher than the concomitant rise in body weight and kidney weight $(11,20)$. Factors responsible for the difference in the developmental patterns of fetal and newborn GFR have not been studied. Inasmuch as GPR was previously suggested as an important factor responsible for the development of GFR in newborn rats (3), the present protocol was designed to study the ontogeny of GPR during the last third of gestation and during the transitional period from fetal to postnatal life. Finally, the influence of those changes in GPR on the postnatal development of GFR was also investigated.

\section{MATERIALS AND METHODS}

\section{ANIMAL PREPARATION AND SURGICAL PROCEDURES}

The fetuses of 20 pregnant sheep of Dorset and Suffolk mixed breeding were studied between 106 and 140 days of gestation (term, 145 days). Six fetuses were between 106 and 119 days, seven between 120 and 130 days, and seven between 131 and 140 days. Gestational ages were based on the induced ovulation technique as described previously (19).

Before surgery the animals were fasted for $48 \mathrm{hr}$. Anesthesia of the ewe and surgery of the fetus were performed as described previously $(19,22)$. After surgery, the ewes were kept in a restricted area and fed a standard diet. Ampicillin ( $1 \mathrm{~g}$ every $8 \mathrm{hr}$ ) was given intramuscularly for the first 3 days after surgery and every time thereafter that the catheters were flushed. All vascular catheters were irrigated daily for the first 3 days with a heparinized saline solution and every other day henceforth. A recovery period of at least 6 days was required before performing experiments. 
Six newborn lambs were also studied between 3 and 19 days of postnatal age. Surgery was performed at least $48 \mathrm{hr}$ before experiments in each lamb. Under general anesthesia using a mixture of halothane, oxygen, and nitrous oxide as previously described, catheters were inserted in the femoral vein and the superficial femoral artery. An additional catheter was also placed in the left ventricle via the opposite superficial femoral artery for injection of microspheres. A 4 French infant feeding tube was placed in the bladder through a suprapubic incision. All catheters were secured as described previously for the fetuses and tunnelled subcutaneously to exit the skin on the animal's flank. In the first $6 \mathrm{hr}$ of recovery, the animals were administered $5 \%$ glucose- $0.25 \%$ saline solution intravenously until the animal was able to feed by mouth. In all cases, the ewe accepted her postoperative lamb and nursed the lamb adequately.

\section{PHYSIOLOGIC STUDIES}

During the physiologic studies, the ewe was transferred into a small cart permitting it to stand only. When newborn lambs were studied, they were immobilized standing in a harness. The GFR in fetal and newborn lambs was determined by a constant infusion of $\left[{ }^{125} \mathrm{I}\right]$ sodium iothalamate (Glofil Abbott Laboratories, North Chicago, IL) into either the fetal or neonatal femoral vein as previously described (22). An equilibration period of $1 \mathrm{hr}$ was then allowed before the start of the first renal clearance period. After the equilibration period, renal clearance was determined during three 20 -min periods. At the midpoint of each clearance period, arterial blood was obtained for determination of plasma concentrations of $\left[{ }^{125} \mathrm{I}\right]$ sodium iothalamate, plasma electrolytes concentrations $\left(\mathrm{Na}^{+}, \mathrm{K}^{+}\right.$, and $\left.\mathrm{Cl}^{-}\right)$, plasma osmolality, hematocrit, arterial blood gases $\left(\mathrm{PCO}_{2}\right.$ and $\left.\mathrm{PO}_{2}\right)$, arterial $\mathrm{pH}$, and total protein concentrations. At the end of each clearance period, urine was collected to determine the urinary concentration of $\left[{ }^{125} \mathrm{I}\right]$ sodium iothalamate. Individual data from each of the three clearance periods were than averaged to obtain a single value.

To prevent hemodynamic changes, fetal blood was replaced with an equal amount of maternal blood after every fetal sample was taken. In the newborn, blood was replaced using an equal volume of plasma protein fraction (Plasmanate; Cutter Laboratories, Berkeley, CA).

Radioactive microspheres, approximately $15 \pm 3 \mu$ in diameter (3M Co., St. Paul, MN) were used as described previously $(9,22)$ to determine the renal blood flow (RBF) and the regional renal cortical blood flow in fetal and newborn lambs. Spheres were provided with either ${ }^{85} \mathrm{Sr}$ or ${ }^{46} \mathrm{Sc}$ incorporated into their structures and were suspended in $10 \%$ dextran to which trace of dispersing agent, Tween 80 , had been added. Before injection, microspheres were thoroughly mixed and placed in an ultrasonic bath for 3 to $5 \mathrm{~min}$ to prevent aggregation. Immediately after the three control urine collection periods, approximately $4.0 \times 10^{6}$ microspheres were suspended in $3 \mathrm{ml}$ of $0.9 \%$ saline solution using a $6 \mathrm{ml}$ plastic syringe and were injected throughout a $30-\mathrm{sec}$ period into the fetal femoral vein catheter or directly into the left ventricle in newborn lambs and then immediately flushed with $3 \mathrm{ml}$ of $0.9 \%$ saline solution. Femoral arterial blood was collected during a period of $3 \mathrm{~min}$ beginning $20 \mathrm{sec}$ before the microspheres injection and at a withdrawal rate of $2.1 \mathrm{ml} / \mathrm{min}$, using an infusion-withdrawal Harvard pump, to obtain a lower body independent reference sample (RF).

Infusion of $1.5 \times 10^{6}$ microspheres in newborns and $4 \times 10^{6}$ in fetal lambs was necessary to get a minimum of 400 spheres per zone of renal cortex analyzed and to decrease counting errors as suggested previously $(4,7)$. To determine if infusion of $4 \times 10^{6}$ microspheres could modify the fetal renal function, in four fetuses, three additional clearance periods were collected after the first bolus of microspheres, and a second bolus of microspheres $(4.0$ $\times 10^{6}$ ) was administered. In those four fetuses, no significant difference was found between the first and second groups of control clearance periods and the determinations of total RBF were similar.
Arterial and venous pressure were recorded continuously in every fetal or newborn lamb using Statham $\mathrm{P} 23 \mathrm{Db}$ pressure transducers (Statham Instruments Division, Gould, Inc.) and a Beckman R-611 recorder. Fetal MABP's were corrected relative to concomitant amniotic pressures. Fetal and newborn heart rates were monitored with a cardiotachometer triggered from the fetal arterial pressure pulse wave. At the end of the experiment, the fetus and newborn were sacrificed with lethal doses of $\mathrm{KCl}$ solution.

\section{ANALYTICAL METHODS}

Blood for $\mathrm{pH}, \mathrm{PCO}_{2}$, and $\mathrm{Po}_{2}$ was collected anaerobically in heparinized glass syringes and measurements were immediately determined with the appropriate $\mathrm{pH}, \mathrm{PCO}_{2}$, and $\mathrm{PO}_{2}$ electrodes at $39^{\circ} \mathrm{C}$ using a Radiometer PHM 72 MK2 acid-base analyzer (Radiometer Co., Copenhagen, Denmark). Plasma osmolality and plasma concentrations of sodium, potassium, and chloride were determined as previously described (22). Concentrations of $\left[{ }^{125} \mathrm{I}\right]$ sodium iothalamate in plasma and urine were determined by gamma emission of $\left[{ }^{125} \mathrm{I}\right]$ using a Beckman-300 gamma spectrometer. Protein content of fetal serum was determined using a refractometer (National Instrument Co., Baltimore, MD).

Gamma emission generated from the microspheres injection was measured from both kidney and reference femoral arterial blood samples. Immediately after removing the kidneys from the animal, they were placed in 10\% formalin and then weighed and cut into two equal halves along the longitudinal axis of the kidney as described previously $(16,22)$. One-half was then cut into sections of less than $1 \mathrm{~g}$ along the longitudinal axis and placed in counting vials. From the second half, one or two sections of approximately $1.5 \mathrm{~mm}$ thick were also cut. From these sections, five blocks, approximately 3 to $4 \mathrm{~mm}$ broad with corticomedullary borderlines parallel to the surface were selected. The cortex was separated from the medulla just below the arcuate vessels and divided into four equally thick slices by cuts paralleling the outer surface and the corticomedullary borderline as previously described by Olbing et al. (16). Each slide designated zones I to IV from the subcapsular area to the juxtamedullary cortex was weighed in preweighed counting tubes containing $1 \mathrm{ml}$ of $10 \%$ formalin, and then radioactivity was determined. Depending on the isotope labeled on microspheres, the energy window ranges were set between 237 to $293 \mathrm{KeV}$ for ${ }^{85} \mathrm{Sr}$ and 367 to $578 \mathrm{KeV}$ for ${ }^{46} \mathrm{Sc}$ with a gain of 500 .

After the determination of radioactive counts in every zone, all slices of kidney from the same zone were pooled and digested together in $50 \mathrm{ml}$ of $12 \% \mathrm{HCl}$ at $37^{\circ} \mathrm{C}$ for $18 \mathrm{hr}$. After digestion, the kidney tissues were washed from $\mathrm{HCl}$ with water and diluted precisely up to $10 \mathrm{ml}$ in a graduated flask. Thereafter, $0.4 \mathrm{ml}$ of this dilution was placed in a counting chamber, and the number of glomeruli was determined under microscope. For each zone, 10 determinations were done. To be sure that only perfused glomeruli were counted, $100 \mathrm{ml}$ of India ink were infused into the animal just before sacrificing with a lethal dose of $\mathrm{KCl}$.

\section{ANATOMICAL STUDIES}

Sections of kidney from fetuses and newborn lambs at various ages were prepared using hematoxylin and eosin stain to determine the degree of anatomical maturation under light microscopy.

Total glomerular number and the relative distribution of glomeruli per cortical zone were determined after estimating the total cortical volume and the volumes of the individual cortex zones according to the method of McNay and Abe (15).

COMPUTATIONS AND DATA ANALYSIS

$\mathrm{RBF}$ was determined according to the following formula: RBF $(\mathrm{ml} / \mathrm{min})=$ total kidney counts $\times$ RF from the femoral artery $(\mathrm{ml} / \mathrm{min}) /$ total femoral blood counts. GPR was determined by the following formula: GPR $(\mathrm{nl} / \mathrm{min})=[\mathrm{qK} \cdot \mathrm{RF}] \div[\mathrm{QF} \cdot \mathrm{G}]$ where $\mathrm{qK}$ corresponds to the radioactivity counts in a particular zone of the cortex and $G$ to the absolute number of perfused 
glomeruli in that particular zone of the cortex. Renal vascular resistance (RVR) was determined according to the following formula: RVR (mm Hg per $m l$ per $\min )=R P P / R B F$ where $R P P$ is the renal perfusion pressure estimated to be equal to the aortic pressure minus the inferior vena caval pressure. The filtration fraction $(\mathrm{FF})$ was determined according to the following formula: $\mathrm{FF}(\%)=\mathrm{GFR} / \mathrm{RPF}$ where RPF is the renal plasma flow (ml/ $\min )$ and is equal to $\mathrm{RBF} \times(1-$ hematocrit $)$.

Unpaired $t$ test and analysis of variance were used to test for differences among means of two or more populations. Regression lines were determined with the least-square formula. The term "significant" is used throughout the paper to describe changes with a total $P$ value of less than 0.05 in a two-sized significance limit. The results are presented as mean \pm S.E.

\section{RESULTS}

\section{ANATOMICAL OBSERVATIONS}

There were significant correlations between fetal age and fetal body weight $(\mathrm{r}=0.88 ; P<0.001)$ and fetal age and total kidney weight $(\mathrm{r}=0.84 ; P<0.001)$.
Histologic evidence of active nephrogenesis, characterized by the presence of ampullary cells, mesenchymal cells, S-shaped structures, and differentiating interstitial tissue were not observed in $f: t$ uses over 130 days of gestation or in newborn lambs (Fig. 1). However, in younger fetuses, S-shaped structures and induction of metanephric mesenchymal differentiation by active ampullary cells were present (Fig. 2).

Figures 1 and 2 also demonstrate that microspheres were found inside glomerular structures, even in very young fetuses. In a few fetuses of less than 120 days of gestation, occasional microspheres were located in preglomerular capillaries; however, more than $97 \%$ of the $15 \mu \mathrm{m}$ microspheres found in the fetal renal cortex were lodged inside the glomeruli.

The cortical profile of glomerular density is presented in Table 1. The number of glomeruli per unit (g) of cortical tissue, as determined in four cortical zones (zone I being the outermost and zone IV the innermost portion of the cortex), did not show any significant changes during fetal life, the number of glomeruli remaining essentially stable in each cortical zone during the last third of gestation. However, a significant decrease in glomerular density was observed in each cortical zone after birth.

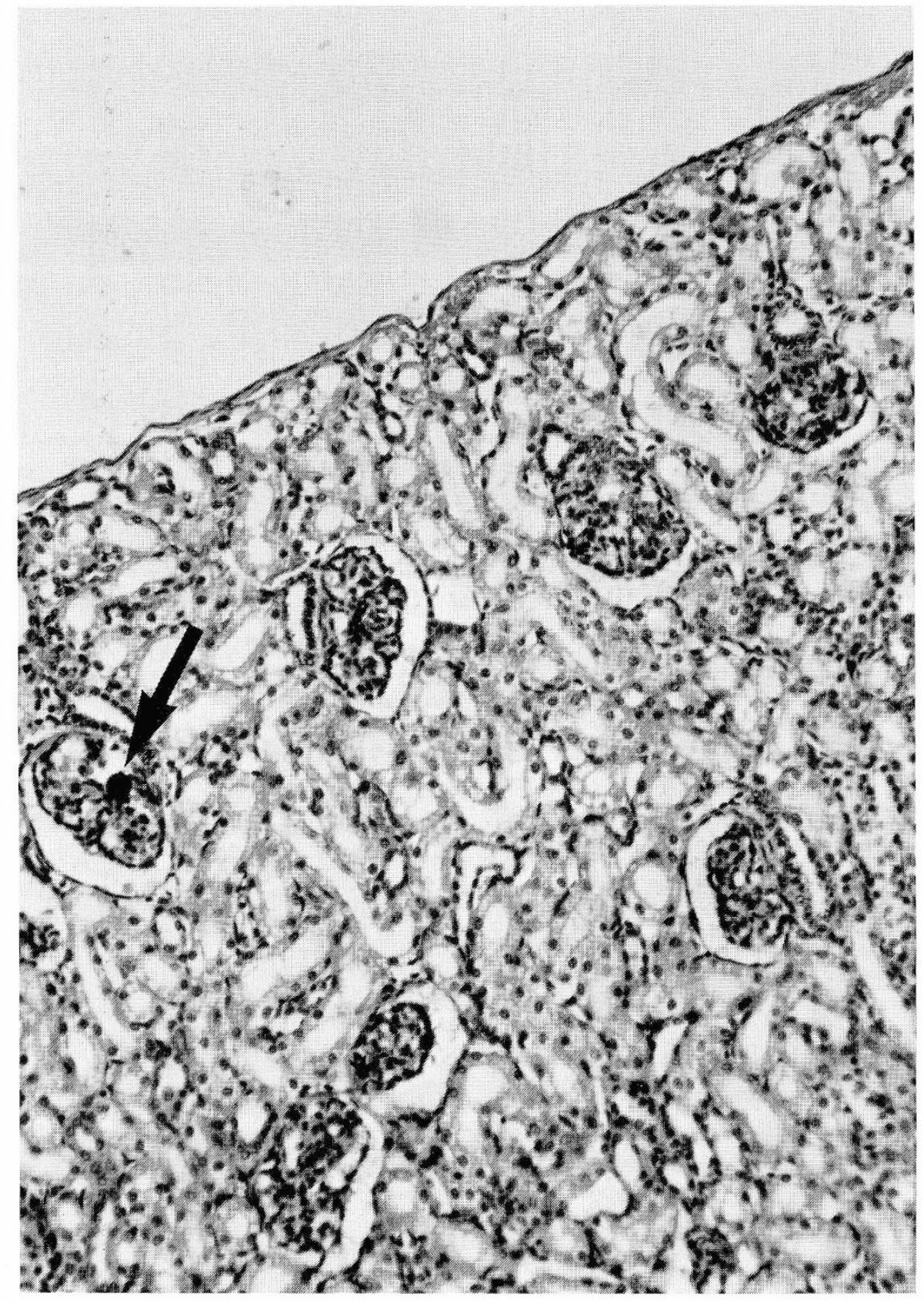

Fig. 1. Photomicrograph of fetal renal cortex from a 140-day fetus. The outer cortex does not show any evidence of nephrogenesis. Microsphere inside a glomerulus is shown by an arrow (original magnification, $\times 125$ ). 


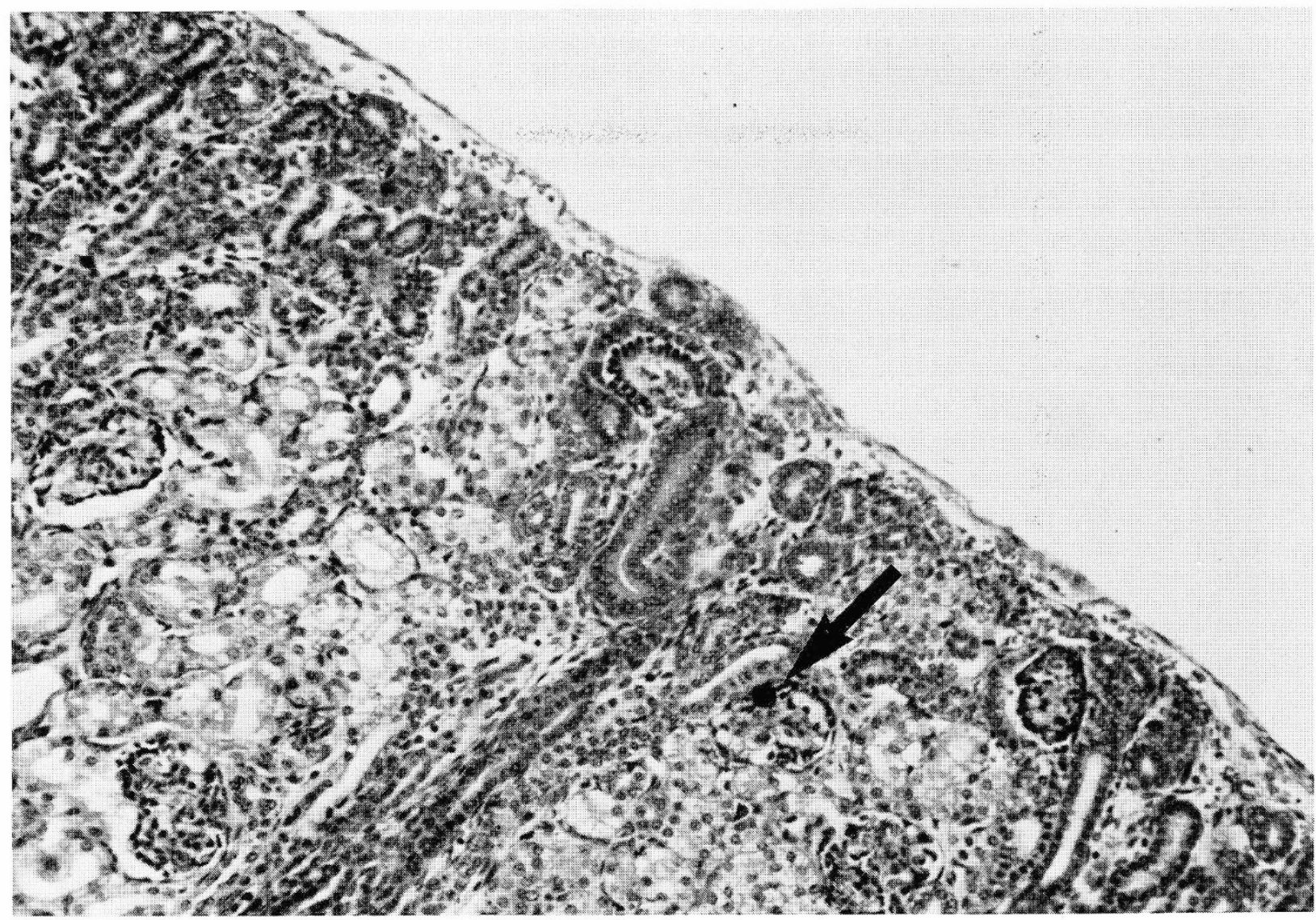

Fig. 2. Photomicrograph of fetal renal cortex from a 116-day fetus. Nephrogenic zone may be seen in the outer cortex. Microsphere inside a glomerulus is shown by an arrow (original magnification, $\times 125$ ).

Table 1. Changes in nephron number per g of cortical zone

\begin{tabular}{|c|c|c|c|c|c|}
\hline & $n^{\prime}$ & Zone I & Zone II & Zone III & Zone IV \\
\hline$<120$ days & 10 & $96576 \pm 7938^{2}$ & $62072 \pm 4476$ & $38077 \pm 4178$ & $20426 \pm 2495$ \\
\hline$>130$ days & 9 & $67651 \pm 9740$ & $66599 \pm 7320$ & $42040 \pm 4738$ & $24045 \pm 2862$ \\
\hline$F$ & & 2.12 & 0.45 & 0.42 & 1.57 \\
\hline Newborns & 8 & $30837 \pm 2824$ & $32366 \pm 3472$ & $24916 \pm 2532$ & $12426 \pm 1421$ \\
\hline$F$ & & 4.01 & 3.23 & 4.70 & 9.54 \\
\hline$P$ & & $<0.05$ & $<0.05$ & $<0.01$ & $<0.01$ \\
\hline
\end{tabular}

' $n$, number of kidneys studied; $F$, values for the $F$ distribution when the means of the different groups of animals are compared.

${ }^{2}$ Mean \pm S.E.

The relative distribution of glomeruli, as shown in Figure 3, decreased in the outer portion (zones I and II) and increased in the inner portion (zones III and IV) of the cortex as fetuses matured and approached term. After birth, this difference became even more prominent when fetuses of less than 120 days of gestation were compared to newborn lambs (Table 2). The outer cortical fraction (zone I) decreased from $49.6 \pm 2.9 \%$ in fetuses of less than 120 days to $37.9 \pm 1.5 \%(P<0.05)$ in newborns whereas the fraction found in zone III increased from $14.9 \pm 1.3$ to 20.8 $\pm 0.7 \%(P<0.05)$. No significant changes were found in zones II and IV during fetal maturation or after birth. Moreover, no significant changes were observed in the relative distribution of glomeruli per zone of cortex when newborns were compared to fetuses over 130 days of gestation.

The total number of glomeruli per kidney was also determined (Table 2). A significant increase in total glomeruli counts were observed during the last trimester of gestation in fetal lambs, the number of glomeruli per kidney increasing from $269420 \pm 24124$ in fetuses of less than 120 days to $468296 \pm 41173$ in fetuses over 130 days gestation $(P<0.01)$. There was no significant difference in total glomerular numbers between fetuses over 130 days of gestation and newborn lambs, suggesting that nephrogenesis was completed before birth in the sheep.

\section{PHYSIOLOGIC OBSERVATIONS}

Arterial blood values are summarized in Table 3. A small but significant decrease in arterial $\mathrm{pH}$ and a significant increase in $\mathrm{PO}_{2}$ were found in newborn lambs when compared to fetuses. The fetal hematocrit increased significantly $(F=5.09 ; P<0.025)$ during the last third of gestation, then decreased after birth. The total protein concentrations increased slowly but significantly just 
before birth $(F=15.6 ; P<0.001)$ and increased even further after birth $(F=68 ; P<0.001)$.

The changes in GFR, total renal blood flow (T-RBF), FF, renal vascular resistance (RVR), and mean arterial blood pressure (MABP) are presented in Table 4 . Small but significant increases in GFR ( $\mathrm{ml} / \mathrm{min})$ and T-RBF $(\mathrm{ml} / \mathrm{min}$ ) were observed during fetal life. Filtration fraction values increased by about $3 \%$ during the last trimester of gestation but the changes were not found to be statistically significant. After birth, FF values showed a $58 \%$ increase while GFR and RBF increased by 630 and $292 \%$, respectively. RVR did not change during the last third of gestation;

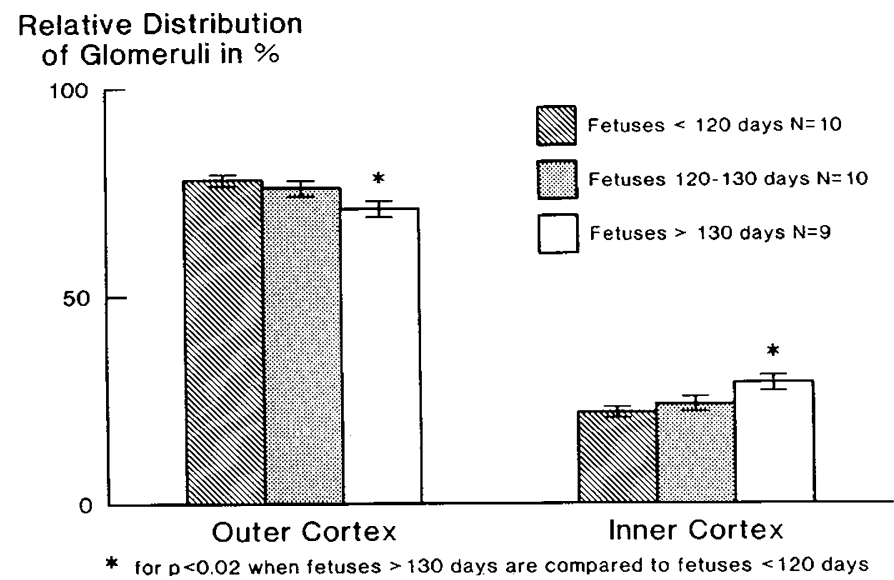

Fig. 3. Relative distribution of glomeruli (\%) across the fetal renal cortex. Outer cortex represents the sum of zones I and II and inner cortex the sum of zones III and IV. Mean \pm S.E. ${ }^{*}, P<0.02$ when fetuses $>130$ days are compared to fetuses $<120$ days. however, a significant decrease was seen after birth. The decrease in RVR after birth was associated with a significant increase in MABP and T-RBF; however, the rise in MABP (88\%) was of lesser magnitude than the rise in RBF (292\%) when the newborn lamb values were compared to fetuses over 130 days of gestation.

Maturational changes in GPR are shown in Table 5. During fetal life, GPR computed for each cortical zone did not change in zone IV when compared to mean fetal GPR values. There was no significant redistribution of GPR between cortical zones during fetal life (Table 5). However, in newborns, GPR was significantly higher in zone I than in zone IV, and a significant $(P<0.001)$ and gradual decrease in GPR from zone I to zone IV was observed.

In newborn lambs, there was a close and significant correlation between the increase in GFR and the increase in GPR in zone I $(\mathrm{r}=0.87 ; P<0.025)$ and in zone II $(\mathrm{r}=0.87 ; P<0.025)$ (Fig. 4). The coefficients of correlation between GFR and GPR in zones III and IV were 0.43 and 0.04 , respectively.

\section{DISCUSSION}

\section{MORPHOLOGIC DEVELOPMENT OF THE FETAL AND NEWBORN LAMB KIDNEYS}

Knowledge of the morphologic development of the fetal and newborn kidney is essential to the understanding of physiological changes occurring during renal maturation. The present results demonstrate for the first time in lambs that the nephrogenic zone disappears around 130 days of gestation (term, 145 days) and that at birth the degree of anatomical maturation is similar to the human. Moreover, induction of new nephrons in the lamb ceases after approximately $90 \%$ of gestation is completed (Table 2 ), as in the human fetus (17). Previous studies in guinea pigs (26) and cattle (8) also demonstrate that, as in humans and sheep, new nephron formation does not occur after birth.

Table 2. Relative distribution (\%) of glomeruli per cortical zone

\begin{tabular}{|c|c|c|c|c|c|c|}
\hline & $n^{1}$ & Zone I & Zone II & Zone III & Zone IV & $\begin{array}{c}\text { Total } \\
\text { glomerular counts }\end{array}$ \\
\hline \multicolumn{7}{|l|}{ Fetuses } \\
\hline $120-130$ days & 10 & $48.6 \pm 5.8$ & $27.2 \pm 3.5$ & $18.0 \pm 1.9$ & $6.2 \pm 1.1$ & $335150 \pm 42572$ \\
\hline$<130$ days & 9 & $38.2 \pm 3.0$ & $33.5 \pm 2.1$ & $19.8 \pm 1.7$ & $8.5 \pm 1.1$ & $468296 \pm 41173$ \\
\hline$F$ & & 3.85 & 1.74 & 3.39 & 1.29 & 8.75 \\
\hline$p$ & & $<0.05$ & NS & $<0.05$ & NS & $<0.01$ \\
\hline
\end{tabular}

${ }^{1} n$, number of kidneys studied; $F$, values for the $F$ distribution when the means of the four groups of animals are compared.

${ }^{2}$ Mean \pm S.E.

Table 3. Arterial blood values

\begin{tabular}{|c|c|c|c|c|c|c|}
\hline & \multicolumn{3}{|c|}{ Fetus } & \multirow[b]{2}{*}{$\begin{array}{c}\text { Newborn }(3-19 \\
\text { days) }(N=6)\end{array}$} & \multirow[b]{2}{*}{$F$} & \multirow[b]{2}{*}{$P$} \\
\hline & $\begin{array}{c}<120 \text { days } \\
(N=6)^{1}\end{array}$ & $\begin{array}{c}120-130 \text { days } \\
(N=7)\end{array}$ & $\begin{array}{c}>130 \text { days } \\
(N=7)\end{array}$ & & & \\
\hline $\mathrm{pH}$ & $7.38 \pm 0.01^{2}$ & $7.39 \pm 0.02$ & $7.38 \pm 0.01$ & $7.33 \pm 0.02$ & 4.93 & $<0.05$ \\
\hline $\mathrm{PCO}_{2}(\mathrm{~mm} \mathrm{Hg})$ & $43 \pm 2$ & $40 \pm 3$ & $43 \pm 2$ & $36 \pm 2$ & 1.90 & NS \\
\hline $\mathrm{PO}_{2}(\mathrm{~mm} \mathrm{Hg})$ & $23 \pm 1$ & $24 \pm 1$ & $20 \pm 1$ & $82 \pm 2$ & 403.0 & $<0.001$ \\
\hline $\mathrm{Na}$ (mEq/liter) & $146 \pm 2$ & $148 \pm 3$ & $149 \pm 1$ & $147 \pm 1$ & 0.48 & NS \\
\hline $\mathrm{K}$ (mEq/liter) & $4.1 \pm 0.2$ & $4.3 \pm 0.3$ & $4.8 \pm 0.3$ & $4.1 \pm 0.1$ & 1.23 & NS \\
\hline $\mathrm{Cl}(\mathrm{mEq} /$ liter $)$ & $105 \pm 2$ & $108 \pm 1$ & $107 \pm 2$ & $111 \pm 2$ & 1.66 & NS \\
\hline Osmolality (mOsm $/ \mathrm{kg} \mathrm{H}_{2} 0$ ) & $292 \pm 2$ & $295 \pm 2$ & $291 \pm 1$ & $295 \pm 3$ & 0.99 & NS \\
\hline Hematocrit (\%) & $29 \pm 1$ & $32 \pm 2$ & $37 \pm 2$ & $26 \pm 3$ & 4.93 & $<0.05$ \\
\hline Total proteins $(\mathrm{g} / 100 \mathrm{ml})$ & $3.2 \pm 0.1$ & $3.2 \pm 0.1$ & $3.7 \pm 0.1$ & $5.5 \pm 0.2$ & 68.00 & $<0.001$ \\
\hline
\end{tabular}

\footnotetext{
${ }^{1} N$, number of animals studied; $F$, values for the $F$ distribution when the means of the four groups of animals are compared

${ }^{2}$ Mean \pm S.E
} 
Table 4. Values for GFR, renal hemodynamics, and MABP in fetuses and newborn lambs

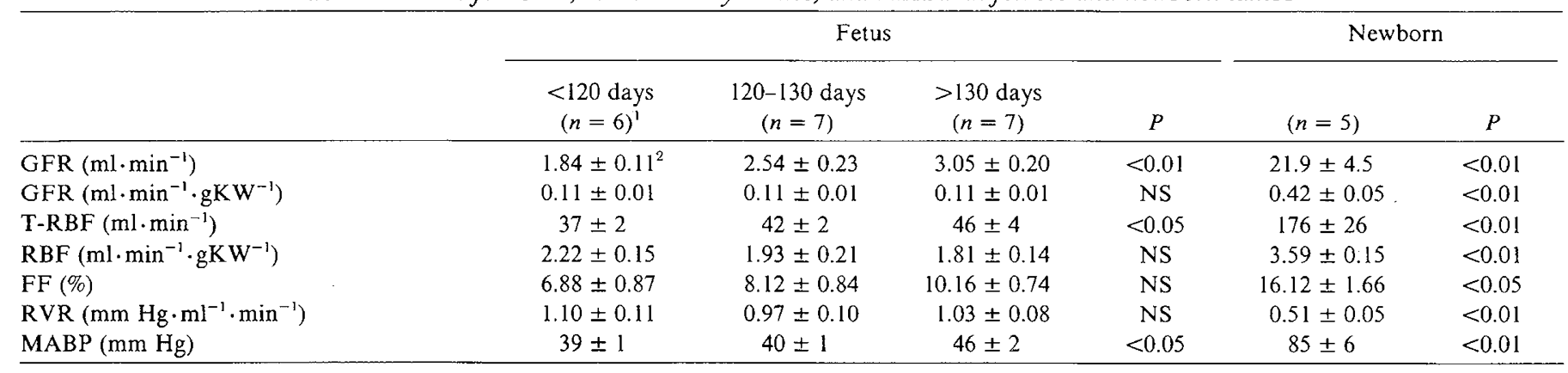

' $n$, number of animals studied. $P$ values were determined by analysis of variance by comparing the means of either the three groups of fetuses or of the three groups of fetuses and newborn lambs.

${ }^{2}$ Mean \pm S.E.

Table 5. Mean values of GPR's ( $\mathrm{nl} / \mathrm{min})$ in fetuses and newborns

\begin{tabular}{|c|c|c|c|c|c|c|c|}
\hline & $n^{\prime}$ & Zone I & Zone II & Zone III & Zone IV & $F$ & $P$ \\
\hline \multicolumn{8}{|l|}{ Fetuses } \\
\hline$<120$ days & 10 & $61.4 \pm 8.2^{2}$ & $72.5 \pm 7.2$ & $71.1 \pm 7.6$ & $70.5 \pm 9.3$ & 0.38 & NS \\
\hline$>130$ days & 9 & $69.2 \pm 8.9$ & $53.6 \pm 4.2$ & $55.6 \pm 10.0$ & $59.7 \pm 4.7$ & 2.02 & NS \\
\hline Newborns & 8 & $206.9 \pm 16.8$ & $161.3 \pm 20.7$ & $119.5 \pm 8.9$ & $79.2 \pm 13.8$ & 12.18 & $<0.001$ \\
\hline$P$ & & $<0.001$ & $<0.001$ & $<0.001$ & NS & & \\
\hline
\end{tabular}

' $n$, number of kidneys studied; $F$, values for $F$ distribution when the means of the four groups of animals or the means of each cortical zone are compared.

${ }^{2}$ Mean \pm S.E.

In the present study, contrary to what has been described during postnatal maturation $(1,3,10,16)$, we found that there is no significant decrease in the number of glomeruli per unit of cortical tissue, in cortical zones I through IV, during fetal life (Table 1), suggesting that the anatomic maturation of the fetal cortex depends more on the addition of new nephron units than on growth of nonglomerular structures. However, the significant decrease in the relative distribution of glomeruli counts in the outer cortex and the significant increase in the inner cortex, when fetuses over 130 days are compared to fetuses of less than 120 days (Fig. 3), suggest that the growth rate of nonglomerular structure becomes more important after completion of nephrogenesis as fetuses approach term.

During the newborn period, it has been previously demonstrated that the number of glomeruli per unit of cortical tissue declines with age in all cortical regions as a consequence of the more rapid growth of nonglomerular structures $(1,3,10,16)$. In the present study, a significant decline in the glomerular count per $g$ of cortical tissue was observed in newborn lambs when compared to fetuses.

\section{DEVELOPMENTAL ASPECTS OF GPR}

In the present study, GPR was determined using radioactive microspheres with an average diameter of approximately $15 \mu$. The microsphere method to be accepted as a reliable measure of glomerular perfusion rate must comply to certain criteria $(25,27)$. We previously demonstrated that sequential infusion of microspheres into the fetal circulation does not modify the fetal renal function and that $15 \mu$ diameter spheres are most suitable to study blood flow distribution in fetal lambs because spheres of smaller diameter $(9 \mu)$ recirculate (23). Moreover, we have shown in the present study that $15 \mu$ spheres are trapped within the glomeruli in fetal and newborn lambs. Another important criterion that must be met if the intrarenal distribution of microspheres is to be used as a reflection of the distribution of blood flow to the glomeruli is that axial streaming of spheres should be avoided ( 6 , 30 ). In the present study, the effect of possible axial streaming in the fetal and newborn renal vasculature was not evaluated. However, the fact that glomerular perfusion rate in zone I (outer cortex) was higher in newborns than in fetuses (Table 5) is against a major effect of axial streaming to explain the redistribution of GPR after birth. Because of relatively smaller blood vessels in fetuses than in newborns, axial streaming should have been more important in fetuses, and therefore, GPR in fetal outer cortex should have been higher than in inner cortex. On the contrary, we found that the GPR values in the outer zone of the fetal cortex were not significantly different from the values measured in the inner cortex, suggesting that axial streaming alone could not have been responsible for the pattern of glomerular blood flow distribution during fetal life.

In the present study, individual values for GPR in fetal and newborn lambs were relatively higher than in previous studies by Aperia et al. $(1,2)$ also using the lamb as experimental animal. The technique used to determine the number of glomeruli was similar in both studies and therefore could not account for the discrepancy. One of the factors that could at least partially explain the discrepancy between both studies is the fact that the cortical zones were not divided similarly in the two studies: four equal zones in the present study, three unequal zones in Aperia's studies $(1,2)$. Finally, it is possible that because Aperia's studies $(1,2)$ were performed under general anesthesia and during surgical stress, the flow per cortical zone was altered. Inasmuch as GPR is determined as the ratio between the flow per cortical zone and the number of perfused glomeruli in that particular zone, a change in cortical flow will modify the GPR values. The present study was done using unanesthetized and unstressed chronically catheterized animals.

The development of GPR during postnatal maturation has been previously studied in rats (3), dogs (16), and lambs $(1,2)$. These studies $(1,2,3,16)$ demonstrated that GPR increased steadily after birth in every cortical zone. Olbing et al. (16) found in 

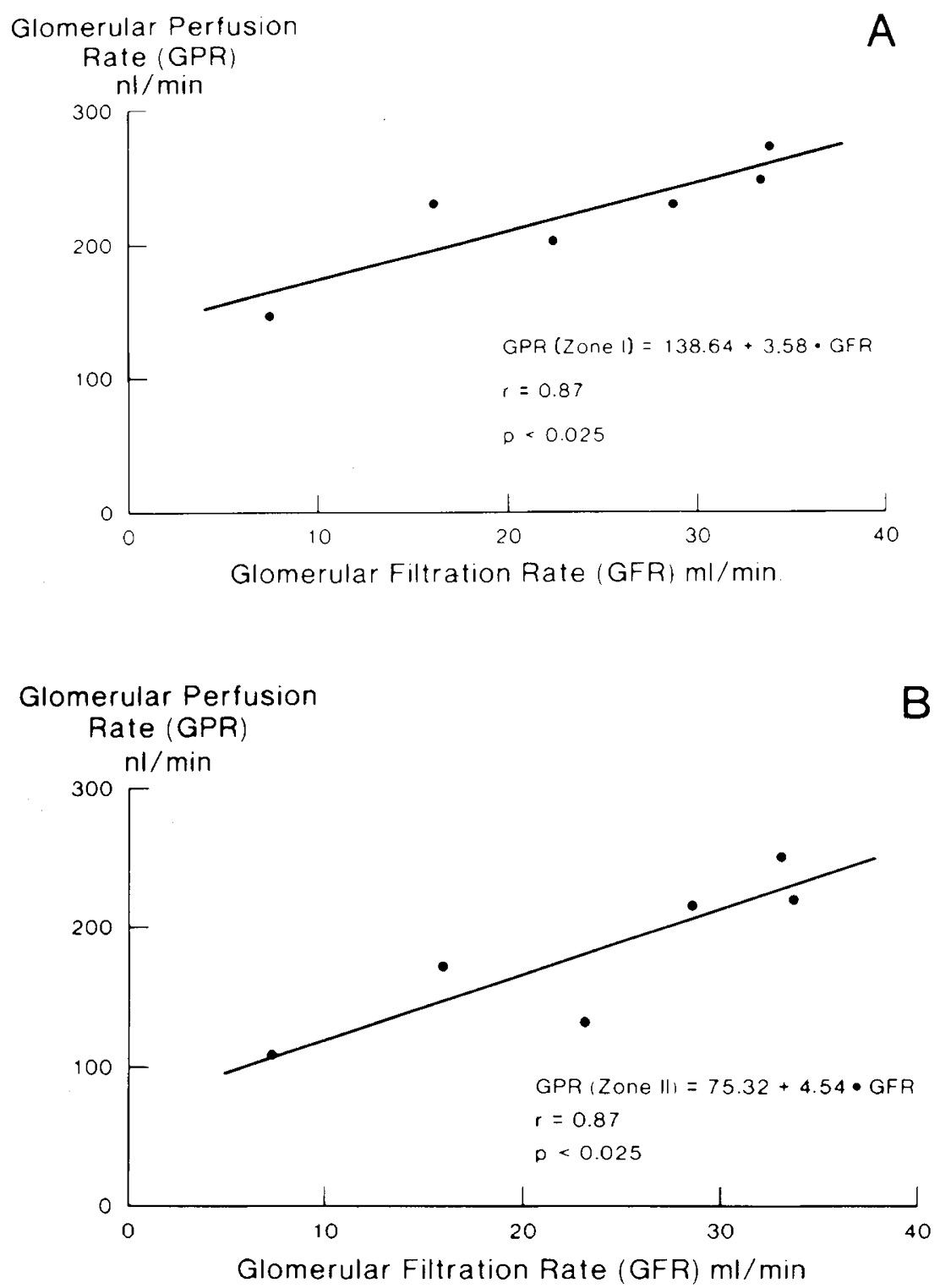

Fig. 4. Relationship between GFR and GPR in zone $\mathrm{I}(A)$ and zone II $(B)$ in newborn lambs between 3 and 19 days of age.

newborn dogs that GPR was lower in the outer than in the inner cortex at birth; however, with maturation it became apparent that a marked increase in perfusion of the outer glomeruli took place. Aperia et al. $(1,2)$ also demonstrated that GPR in newborn lambs increased in outer, mid, and inner cortex during postnatal maturation; however; in contrast to Olbing et al.'s study (16), it was found that during the first wk of life in lambs GPR was higher in the outer cortex than in the inner cortex. Aperia et al. $(1,2)$ suggested that the discrepancy between their and Olbing's results (16) might have been secondary to differences in the anatomical maturation of lamb and dog kidneys because nephrogenesis in dogs continues during the first 3 wk after birth.

In the present study, the fetal GPR remained stable in all four cortical zones (Table 5) during the last third of gestation. After birth, GPR values increased significantly in the outer zones of the cortex when no changes were observed in the inner cortex (zone IV) when compared to fetal values. Many factors may have contributed to this increase in GPR after birth. In previous studies, Aperia et al. (1) suggested that the rise in GPR during postnatal maturation was related, at least partially, to an increase in cardiac output. Kleinman and Reuter (14) found a close correlation between the redistribution of blood flow toward the outer cortex and the increase in arterial blood pressure during postnatal development, suggesting that maturation of glomerular blood flow might be related to the maturation of arterial blood pressure.
However, Olbing et al. (16) were unable to confirm Kleinman and Reuter's results (14), and more recently Aperia and Herin (3) suggested that changes in arterial pressure do not necessarily relate to changes in GPR.

The present study was not designed to study the factors modulating the changes in GPR during the transition period from intrauterine to extrauterine life. However, because the rapid increase in GPR after birth was not associated with the formation of new nephron units, one can speculate that a decrease of glomerular vascular resistance is a major determinant in the postnatal increase in GPR. Other factors such as a decrease in hematocrit (24), increase in total plasma protein concentration (29), and an increase in glomerular size may also have contributed to the increase in GPR when newborn lambs were compared to fetuses.

During fetal life, the increase in GFR did not correlate with GPR at any cortical level. However, as previously shown $(18,21)$, fetal GFR correlates closely with the increase in kidney weight, suggesting that one of the major determinants of fetal GFR still remains the addition of new nephron units in fetuses of less than 130 days of gestation. In fetuses over 130 days of gestation, because the active nephrogenesis is completed, the addition of new nephron units cannot be a major determinant to explain the increase in GFR at that time. Other factors such as increases in surface area for filtration, effective filtration pressure, and capillary filtra- 
tion coefficient may play an important role in the maturation of GFR just before birth; however, the present investigation was not designed to study these factors. After birth, there is an abrupt rise in GFR that is greater than the rise in kidney weight (20). Furthermore, this increase in GFR correlated closely with the increase in GPR in zone $\mathrm{I}(\mathrm{r}=0.87)$ and in zone II $(\mathrm{r}=0.87)$, suggesting that the developmental pattern of GFR after birth may depend, at least partially, on the increase in GPR in the outer cortex. Aperia and Herin (3) previously suggested, on the basis of simultaneous measurements of single nephron glomerular filtration rate and GPR in newborn rats, that the major factor responsible for the development of GFR during the period of postnatal maturation is the increase in GPR. Similar results were also found by Ichikawa et al. (12) in Munich-Wistar rats between 30 and 45 days of age, and it was suggested that high afferent and efferent arteriolar resistance were the main modulators of the low glomerular plasma flow in immature rats. Tucker and Blantz (28) also suggested that in addition to the increase in glomerular plasma flow, the increase in glomerular permeability coefficients is a major contributor to the increase in single nephron glomerular filtration rate after birth.

In summary, we have demonstrated that active nephrogenesis stops at approximately 130 days of gestation in fetal lambs and that kidney growth during fetal life depends more on the addition of new nephron units than on growth of nonglomerular structures. Moreover, we also demonstrated that fetal GPR did not change during the last third of gestation but increased significantly in the outer zones of the cortex after birth. Finally, these studies suggest that the increase in GPR after birth is an important modulator in the rapid rise in GFR during postnatal life.

\section{REFERENCES AND NOTES}

1. Aperia, A., Broberger, O., and Herin, P.: Maturational changes in glomerular perfusion rate and glomerular filtration rate in lambs. Pediatr. Res., 8: 758 (1974).

2. Aperia, A., Broberger, O., Herin, P., and Joelsson, I.: Renal hemodynamics in the perinatal period. Acta Physiol. Scand., 99: 261, (1977).

3. Aperia, A., and Herin, P.: Development of glomerular perfusion rate and nephron filtration rate in rats 17-60 days old. Am. J. Physiol., 228: 1319 (1975).

4. Archie, J. P., Fixler, D. E., Ullyot, D. J., Hoffman, J. I. E., Utley, J. R., and Carlson, E. L.: Measurement of cardiac output with end organ trapping of radioactive microspheres. J. Appl. Physiol., 35: 148 (1973)

5. Aschinberg, L. C., Goldsmith, D. I., Olbing, H., Spitzer, A., Edelmann, C. M., and Blaufox, M. D.: Neonatal changes in renal blood flow distribution in puppies. Am. J. Physiol., 228: 1453 (1975).

6. Bankir, L., Tan, T. T., and Grunfeld, J. P.: Measurement of glomerular blood flow in rabbits and rats: erroneous findings with $15-\mu \mathrm{m}$ microspheres. Kidney Int., 15: 126 (1979).

7. Buckerg, G. D., Luck, J. C., Payne, B., Hoffman, J. I. E., Archie, J. P., and Fixler, D. E.: Some sources of error in measuring regional blood flow with radioactive microspheres. J. Appl. Physiol., 31: 598 (1971).

8. Cade-Treyer, D., and Tsuji, S.: In vitro culture of the proximal tubule of the bovine nephron. Cell Tissue Res., 163: 15 (1975).

9. Heymann, M. A., Payne, B. D., Hoffman, J. I. E., and Rudolph, A. M.: Blood flow measurements with radionuclide-labelled particles. Prog. Cardiovasc. Dis., 20: 55 (1977).
10. Horster, M., Kemler, B. J., and Valtin, H.: Intracortical distribution of number and volume of glomeruli during postnatal maturation in the dog. J. Clin. Invest., 50: 796 (1971).

11. Horster, M., and Valtin, H.: Postnatal development of renal function. Micropuncture and clearance studies in the dog. J. Clin. Invest., 50: 779 (1971).

12. Ichikawa, I., Maddox, D. A., and Brenner, B. M.: Maturational development of glomerular ultrafilitration in the rat. Am. J. Physiol., 236: F465 (1979).

13. Jose, P. A., Logan, A. G., Slotkoff, L. M., Lilienfield, L. S., Calcagno, P. L., and Eisner, G. M.: Intrarenal blood flow distribution in canine puppies. Pediatr. Res., 5: 335 (1971).

14. Kleinman, L. I., and Reuter, J. H.: Maturation of glomerular blood flow distribution in the newborn dog. J. Physiol. (Lond.), 228: 91 (1973).

15. McNay, J. L., and Abe, Y.: Pressure dependent heterogeneity of renal cortical blood flow in dogs. Circ. Res., 27: 571 (1970)

16. Olbing, H., Blaufox, M. D., Aschinberg, L. C., Silkans, G. I., Bernstein, J. Spitzer, A., and Edelmann, C. M., Jr.: Postnatal changes in renal glomerular blood flow distribution in puppies. J. Clin. Invest., 52: 2885 (1973).

17. Potter, E. L.: Development of the human glomerulus. Arch. Pathol., 80: 241 (1965).

18. Robillard, J. E., Kulvinskas, C.. Sessions, C., Burmeister, L., and Smith, F. G., Jr.: Maturational changes in the fetal glomerular filtration rate. Amer. J. Obstet. Gynecol., 122: 601 (1975).

19. Robillard, J. E., Matson, J. R., Sessions, C., and Smith, F. G., Jr.: Developmental aspects of renal tubular reabsorption of water in the lamb fetus. Pediatr. Res., 13: 1172 (1979).

20. Robillard, J. E., Ramberg, E., Sessions, C. Consamus, B., VanOrden, D. Weismann, D., and Smith, F. G., Jr.: Role of aldosterone on renal sodium and potassium excretion during fetal life and newborn period. Dev. Pharmacol. Ther., l: 201 (1980).

21. Robillard, J. E., Sessions, C., Kennedy, R. L., Robillard, L. H., and Smith, F. G., $\mathrm{Jr}$.: Interrelationship between glomerular filtration rate and renal transport of sodium and chloride during fetal life. Am. J. Obstet. Gynecol., 128: 727 (1977).

22. Robillard, J. E., and Weitzman, R.: Developmental aspects of the fetal renal response to exogenous arginine vasopressin. Am. J. Physiol. 238: F407 (1980).

23. Robillard, J. E., Weitzman, R. E., Burmeister, L., and Smith, F. G., Jr.: Developmental aspects of the renal response to hypoxemia in the lamb fetus. Circ. Res., 48: 128 (1981).

24. Schrier, R. W., and Earley, L. E.: Effects of acute changes of hematocrit on renal hemodynamics and sodium excretion in hydropenic and volume-expanded dogs. J. Clin. Invest., 49: 1656 (1970).

25. Slotkoff, L. M., Logan, A., Jose, P., D’Avella, J., and Eisner, G. M.: Microsphere measurement of intrarenal circulation of the dog. Circ. Res., 28: 158 (1971).

26. Spitzer, A., and Brandis, M.: Functional and morphologic maturation of the superficial nephrons. Relationship to total kidney function. J. Clin. Invest., 53: $279,(1974)$.

27. Stein, J. H., Terris, T. F., Huprich, J. E., Smith, T. C., and Osgood, R. W.: Effect of renal vasodilatation on the distribution of cortical blood flow in the kidney of the dog. J. Clin. Invest.. 50: 1429 (1971)

28. Tucker. B. J., and Blantz, R. C.: Factors determining superficial nephron filtration in the mature growing rat. Am. J. Physiol. 232: F97 (1977).

29. Vereerstraeten. P., and Taussaint, C.: Effects of plasmapheresis on renal hemodynamics and sodium excretion in dogs. Pfluegers Arch. Eur. J. Physiol., 306: $92(1969)$.

30. Yarger, W. E., Boyd, M. A., and Schrader, N. W.: Evaluation of methods of measuring glomerular and nutrient blood flow in rat kidneys. Am. J. Physiol., 235: $\mathrm{H} 592$ (1978).

31. Requests for reprints should be addressed to: Jean E. Robillard, M.D. Department of Pediatrics, University of Iowa Hospitals, Iowa City. IA 52242 (USA).

32. This research was supported by United States Public Health Service Grants HD11466 and HL-14388 and American Heart Association Grant 79-809. Dr. Jean E. Robillard is the recipient of Research Career Development Award HD00254, and Dr. Douglas N. Weismann is the recipient of Clinical Investigator Award AM-00656.

33. Received for publication May 15,1980

34. Accepted for publication February 17, 1981 